\title{
Decreasing dietary fat saturation lowers HDL-cholesterol and increases hepatic HDL binding in hamsters
}

\author{
A. H. M. Terpstra ${ }^{1}$, P. van den Berg ${ }^{2}$, H. Jansen ${ }^{2}$, A. C. Beynen ${ }^{1}$ and A. van Tol ${ }^{2}$ \\ ${ }^{1}$ Department of Laboratory Animal Science, Faculty of Veterinary Medicine, Utrecht University, Utrecht, The Netherlands \\ ${ }^{2}$ Department of Biochemistry, Cardiovascular Research Institute COEUR, Erasmus University, Rotterdam, The Netherlands
}

(Received 2 February 1999 - Revised 26 July 1999 - Accepted 16 August 1999)

\begin{abstract}
In order to study the mechanism by which increasing unsaturation of dietary fat lowers HDLcholesterol levels, we studied various measures of HDL metabolism in hamsters fed with fats with different degrees of saturation. Hamsters were fed on a cholesterol-enriched $(1 \mathrm{~g} / \mathrm{kg})$ semipurified diet containing $200 \mathrm{~g} / \mathrm{kg}$ of maize oil, olive oil, or palm oil for 9 weeks. Increasing saturation of dietary fat resulted in increasing concentrations of total plasma cholesterol (4.29 (SD 0.51), 5.30 (SD 0.67) and 5.58 (SD 0.76) mmol/1 respectively, $n$ 12) and HDL-cholesterol (3.31 (SD 0.50), 3.91 (SD 0.12) and $3.97(\mathrm{SD} 0.43) \mathrm{mmol} / \mathrm{l})$ and these concentrations were significantly higher $(P<0.05)$ in the palm-oil and olive-oil-fed hamsters compared with the maize-oil group. Total plasma triacylglycerol levels also increased with increasing fat saturation (1.01 (SD 0.59), 1.56 (SD 0.65) and $2.75(\mathrm{SD} 1.03) \mathrm{mmol} / \mathrm{l})$ and were significantly higher $(P<0.05)$ in the palm-oil group compared with the olive-oil and maize-oil-fed hamsters. The three diets did not have differential effects on plasma activity levels of lecithin: cholesterol acyltransferase (LCAT) and cholesteryl ester transfer protein (CETP). Levels of phospholipid transfer protein (PLTP) tended to be higher with increasing fat saturation but this effect was not significant. The capacity of liver membranes to bind human $\mathrm{HDL}_{3}$ was significantly higher $(P<0.05)$ in the hamsters fed with maize oil (810 (SD 100) ng $\mathrm{HDL}_{3}$ protein/mg membrane protein, $\left.n 4\right)$ compared with those fed on palm oil (655 (SD 56) ng/mg), whereas the olive-oil group had intermediate values (674 (SD 26) $\mathrm{ng} / \mathrm{mg}$ ). The affinity of $\mathrm{HDL}_{3}$ for the binding sites was not affected by the type of dietary fat. Hepatic lipase (EC 3.1.1.3) activity, measured in liver homogenates, increased with increasing fat saturation. We conclude that dietary maize oil, when compared with either olive oil or palm oil, may lower HDL-cholesterol concentrations by enhancing HDL binding to liver membranes.
\end{abstract}

Dietary fat: Lipoproteins: HDL binding: Hamsters

There is considerable evidence that the type of dietary fat can affect plasma cholesterol concentrations and lipoprotein metabolism. Intervention studies (McNamara, 1992; Khosla \& Sundram, 1996) have indicated that high levels of saturated fatty acids in the diet are associated with increased plasma cholesterol concentrations. Replacement of saturated fat by unsaturated fatty acids, on the other hand, results in a lowering of plasma cholesterol concentrations. This plasma cholesterol lowering effect is associated with a decrease in both LDL- and HDL-cholesterol fractions (Khosla \& Sundram, 1996).

Many studies have been carried out to unravel the mechanism by which dietary fatty acids can affect plasma cholesterol concentrations and lipoprotein metabolism. Frequently, animal models have been used (Khosla \& Sundram, 1996), and recently, the hamster has become a popular model to study the effects of drugs and diet on lipoprotein metabolism (Dietschy et al. 1993). The hamster has a lipoprotein profile that resembles more closely that of man than those of rats and mice (Bravo et al. 1994). In addition, the hamster, like man, has plasma cholesteryl ester transfer protein (CETP) activity (Stein et al. 1990). In contrast, other animal models like the pig, mouse, and rat have virtually no plasma CETP activity. Furthermore, changes in plasma lipid concentrations can be easily induced in hamsters with only small, realistic amounts of dietary cholesterol (Dietschy et al. 1993).

The effects of dietary fat saturation on LDL metabolism have been extensively studied in the hamster. Dietschy et al. (1993) reported that substitution of unsaturated for saturated fatty acids results in increased LDL-receptor activity and in a decreased LDL transport rate, which is associated with 
decreased plasma LDL-cholesterol concentrations. Recent studies in hamsters by others (Sessions \& Salter, 1995) have also provided evidence of increased LDL-receptor activity due to feeding unsaturated instead of saturated fatty acids.

Limited information, however, is available on the effects of dietary fat saturation on HDL metabolism in the hamster, while the available results are not consistent. Ahn et al. (1994) reported that soyabean oil compared with coconut oil, given for a period of 18 weeks, resulted in reduced expression of apolipoprotein A-II which was associated with lower HDL-cholesterol concentrations and a larger proportion of small HDL particles. Similar results were reported by Trautwein et al. (1997). They blended different fats and obtained six diets with very different fatty acid profiles to which $4 \mathrm{~g}$ cholesterol $/ \mathrm{kg}$ was added. A lowering of plasma cholesterol levels due to decreasing fat saturation was found to be associated with a lowering of HDLcholesterol levels. Studies by Kurushima et al. (1995), on the other hand, indicated that replacement of dietary palmitic acid by oleic acid lowered plasma cholesterol levels but did not affect HDL-cholesterol concentrations.

The objective of the present study was to study further the mechanism by which increasing fat saturation lowers plasma, and particularly HDL, cholesterol concentrations. We fed hamsters on semipurified diets containing palm oil, olive oil, or maize oil and studied various measures of HDL metabolism, such as hepatic lipase (EC 3.1.1.3) activity, CETP activity, phospholipid transfer protein (PLTP) activity, and lecithin: cholesterol acyltransferase (LCAT) activity, as well as the capacity of liver membranes to bind HDL. It was anticipated that these measures would provide clues as to how dietary fatty acids influence HDLcholesterol concentrations.

\section{Materials and methods}

\section{Animals and diets}

Male Golden Syrian hamsters (Mesocritus auratus; HsdCpb:ShGa) of 5 weeks of age were obtained from Harlan CPB, Zeist, The Netherlands, and were fed on a commercial rodent diet (RMH-B ${ }^{\circledR}$, Hope Farms, Woerden, The Netherlands). After an adaptation period of 2 weeks, blood samples were taken for lipid measurements as described later and the hamsters were divided into three groups so that group means and distributions of total plasma cholesterol concentrations, HDL-cholesterol concentrations, and body weights were similar. Subsequently, the three groups were fed on pelleted semipurified diets (Table 1) containing either palm oil, olive oil or maize oil. The diets were given for a period of 9 weeks. Food and water were provided ad libitum. The hamsters were housed in groups of three or four animals in polycarbonate cages with a bedding of wood shavings. The animal room was temperaturecontrolled $\left(20^{\circ}\right)$ and had a $12 \mathrm{~h}$ light-dark cycle (light on 06.00-18.00 hours). The experimental protocol was approved by the Animal Experiments Committee of the Faculty of Veterinary Medicine, Utrecht University, The Netherlands.
Table 1. Composition of the semipurified diets*

\begin{tabular}{|c|c|c|}
\hline \multirow[b]{2}{*}{ Ingredient } & \multicolumn{2}{|c|}{ Content } \\
\hline & $\mathrm{g} / \mathrm{kg}$ & \% energy \\
\hline Casein & 200 & $17 \cdot 28$ \\
\hline Total fat & 200 & 38.88 \\
\hline Maize oil & 10 & 1.94 \\
\hline Maize/olive/palm oil & 190 & 36.94 \\
\hline Total carbohydrates & 488.15 & $42 \cdot 16$ \\
\hline Maize starch & $244 \cdot 15$ & 21.08 \\
\hline Dextrose & 244 & 21.08 \\
\hline Cellulose & 50 & \\
\hline $\mathrm{CaCO}_{3}$ & $12 \cdot 4$ & \\
\hline $\mathrm{NaH}_{2} \mathrm{PO}_{4} \cdot 2 \mathrm{H}_{2} \mathrm{O}$ & $15 \cdot 1$ & \\
\hline $\mathrm{MgCO}_{3}$ & 1.4 & \\
\hline $\mathrm{KCl}$ & 1.0 & \\
\hline $\mathrm{KHCO}_{3}$ & $7 \cdot 7$ & \\
\hline Inositol & $1 \cdot 25$ & \\
\hline Mineral premix $†$ & 10 & 0.83 \\
\hline Vitamin premix $\ddagger$ & 12 & 0.85 \\
\hline Cholesterol & 1.0 & \\
\hline Total & $1000 \cdot 0$ & 100 \\
\hline
\end{tabular}

* The diets contained $19370 \mathrm{~kJ}$ metabolizable energy $/ \mathrm{kg}$. The following values were used for the calculation of the energy density of the various components: protein and carbohydrates, $16.74 \mathrm{~kJ} / \mathrm{g} ;$ fat, $37.66 \mathrm{~kJ} / \mathrm{g}$. The diets contained $52 \mathrm{mg}$ cholesterol/MJ. Maize oil contained $(\mathrm{g} / 100 \mathrm{~g}$ total fatty acids): 13 saturated, 25 monounsaturated, and 62 polyunsaturated fatty acids; olive oil contained 14 saturated, 77 monounsaturated, and 9 polyunsaturated fatty acids; palm oil contained 51 saturated, 39 monunsaturated, and 10 polyunsaturated fatty acids. The calculated polyunsaturated: saturated fatty acid ratios of the maize-, olive- and palm-oil diets were 4.77, 0.84, and 0.26 respectively.

†Composition (mg/kg food): $\mathrm{FeSO}_{4} .7 \mathrm{H}_{2} \mathrm{O}$ 174, ( $\left.\mathrm{Fe} 35\right), \mathrm{MnO}_{2} 79$, ( $\mathrm{Mn} \mathrm{50}$ ), $\mathrm{ZnSO}_{4} \cdot \mathrm{H}_{2} \mathrm{O} 33,(\mathrm{Zn} \mathrm{12}), \mathrm{NiSO}_{4} \cdot 6 \mathrm{H}_{2} \mathrm{O} 13,(\mathrm{Ni} 3), \mathrm{NaF} 2$, (F 1), KI 0.2, (I 0.15 ), $\mathrm{CuSO}_{4} .5 \mathrm{H}_{2} \mathrm{O}$ 15.7, ( $\mathrm{Cu} 4$ ), $\mathrm{Na}_{2} \mathrm{SeO}_{3} .5 \mathrm{H}_{2} \mathrm{O} 0.3$, (Se 0.10), $\mathrm{CrCl}_{3} .6 \mathrm{H}_{2} \mathrm{O} 1.5$, (Cr 0.30), $\mathrm{SnCl}_{2} .2 \mathrm{H}_{2} \mathrm{O} 1.9,(\mathrm{Sn} \mathrm{1}), \mathrm{NH}_{4} \mathrm{VO}_{3} 0.2$, (V 0.1), maize meal (carrier material) 9679.2.

$\mp$ Composition ( $\mathrm{mg} / \mathrm{kg}$ food): thiamin hydrochloride 4, riboflavin 3 , nicotinamide 20 , calcium pantothenate $(45 \%) 17 \cdot 8$, pyridoxine hydrochloride 6 , cyanocobalamin (purity $0.1 \%$ ) 50 , choline chloride (purity $50 \%$ ) 2000, pteroylmonoglutamic acid 1 , biotin 2 , menadione 0.05 , all-rac- $\alpha$-tocopheryl acetate (purity $50 \%) 60$, retinyl acetate $(150 \mu \mathrm{g} / \mathrm{mg}) 8$, cholecalciferol $(12.5 \mu \mathrm{g} / \mathrm{mg}) 2$, maize meal (carrier material) 9826.15.

\section{Analytical methods}

Blood was collected into heparinized tubes from the retroorbital sinus of the hamsters while they were under light diethyl ether anaesthesia. Food was always removed at 17.00 hours and any food in the cheek pouches was also removed. Blood samples were taken the next day between 09.00 and 11.00 hours. This procedure of blood sampling was used for all the time points that blood was collected. The hamsters were anaesthetized at the end of the experiment with a mixture of ketamine $(140 \mathrm{mg} / \mathrm{kg}$ body weight $)$, xylazine $(24 \mathrm{mg} / \mathrm{kg})$, and atropine $(0.4 \mathrm{mg} / \mathrm{kg})$ which was administered intraperitoneally. The hamsters were then exsanguinated from the abdominal aorta and the livers were removed.

Plasma cholesterol (Allain et al. 1974) and triacylglycerol (Bucolo \& David, 1973) concentrations were measured enzymically. The plasma non-HDL fraction was precipitated with phosphotungstic acid- $\mathrm{MgCl}_{2}$ (Sigma Diagnostics, St Louis, MO, USA; catalogue no. 352-4) according to Weingand \& Daggy (1990), and the supernatant (HDL) fraction was assayed for cholesterol. The concentration of cholesterol in the non-HDL fraction was calculated as the difference between whole plasma and HDL-cholesterol. 


\section{Lecithin: cholesterol acyltransferase activity}

Plasma LCAT activity levels were determined with excess exogenous substrate composed of heat-inactivated human plasma containing $\left[{ }^{3} \mathrm{H}\right]$ cholesterol as described previously (Dullaart et al. 1994). The measured activities are an estimate of LCAT mass and are independent of the endogenous lipoproteins present in each plasma sample. The activities are expressed in $\mu \mathrm{mol}$ cholesteryl ester formed/1 plasma per h. A reference human plasma sample was included in each analysis.

\section{Cholesteryl ester transfer protein activity}

CETP activity in plasma was measured, using exogenous substrates, by transfer of radiolabelled cholesteryl $\left[1-{ }^{14} \mathrm{C}\right.$ ]oleate (Amersham International, Little Chalfont, Bucks, UK; specific activity $1.85 \mathrm{GBq} / \mathrm{mmol}$ ) between exogenous LDL and HDL as described previously (Groener et al. 1986). Briefly, the non-HDL fraction from plasma samples was precipitated with phosphotungstic acid- $\mathrm{MgCl}_{2}$. The supernatant fraction $(60 \mu \mathrm{l})$ was mixed with $500 \mathrm{nmol}$ radiolabelled human LDL-cholesterol and 200 nmol human HDL-cholesterol in a total volume of $700 \mu$ l. 5.5-Dithiobis(2-nitrobenzoic acid) was added to inhibit the LCAT activity. The mixture was incubated for $16 \mathrm{~h}$ at $37^{\circ}$. The incubation was stopped by cooling on ice, and LDL was precipitated with $300 \mu \mathrm{l} 0 \cdot 1 \mathrm{M}$-sodium phosphate $(\mathrm{pH} 7 \cdot 4)$ and $167 \mu \mathrm{l} 0 \cdot 1 \mathrm{M}-\mathrm{MnCl}_{2}$ solution. The samples were centrifuged and the supernatant fraction (containing the HDL) was assayed for radioactivity. The CETP activity measured by this method is linear in time for at least $16 \mathrm{~h}$ and is also linearly related to the amount of supernatant fraction added. The activity is expressed as $\mu \mathrm{mol}$ cholesteryl ester transferred/l plasma per h. A reference human plasma sample was included in each analysis.

\section{Phospholipid transfer protein activity}

PLTP activity was measured in a phospholipid vesiclesHDL assay system as described previously (Speijer et al. 1991). In short, radiolabelled vesicles were prepared by mixing $10 \mu \mathrm{mol}$ egg phosphatidylcholine with $37 \mathrm{kBq}$ $\left[{ }^{3} \mathrm{H}\right]$ phosphatidylcholine (L-3-phosphatidyl[N-methyl- $\left.{ }^{3} \mathrm{H}\right]-$ choline,1,2-dipalmitoyl; Amersham International; specific activity $3.00 \mathrm{TBq} / \mathrm{mmol}$ ) and $0 \cdot 1 \mu \mathrm{mol}$ butylated hydroxytoluene. The lipids were dried under $\mathrm{N}_{2}$, and $1 \mathrm{ml} 150 \mathrm{mM}-$ $\mathrm{NaCl}$ containing $10 \mathrm{mmol}$ Tris- $\mathrm{HCl} / \mathrm{l}$ and $1 \mathrm{mmol}$ EDTA ( $\mathrm{pH} 7.4) / 1$ was added. The lipids were dispersed by sonicating three times for $5 \mathrm{~min}$ on ice with a probe-type sonifier. Plasma samples of $1 \mu \mathrm{l}$ were incubated with radiolabelled vesicles (125 nmol phosphatidylcholine) and human HDL (160 nmol phosphatidylcholine) for $45 \mathrm{~min}$ at $37^{\circ}$ in a total volume of $400 \mu \mathrm{l}$ of $150 \mathrm{mM}-\mathrm{NaCl}, 10 \mathrm{mM}$-Tris- $\mathrm{HCl}$, and 1 mM-EDTA (pH 7.4). The reaction was stopped on ice. A solution containing $500 \mathrm{mM}-\mathrm{NaCl}, 215 \mathrm{mM}-\mathrm{MnCl}_{2}$ and 140 units heparin $(300 \mu \mathrm{l})$ was added and mixed. This yielded final concentrations of $300 \mathrm{mM}-\mathrm{NaCl}, 92 \mathrm{mM}-$ $\mathrm{MnCl}_{2}$, and 200 units heparin/ml. The resulting precipitate was removed by centrifugation and the supernatant fraction assayed for radioactivity. The activity is expressed in mmol phosphatidylcholine transferred to HDL/l plasma per h. A human reference plasma sample was included in each analysis. This assay is specific for PLTP activity, since CETP, which does promote exchange of phospholipids between lipoproteins, shows no activity in this assay (Speijer et al. 1991).

\section{Binding of human HDL to liver membranes}

This assay measures the level of saturable, high-affinity binding sites for HDL on hepatic membranes and is comparable to the tests used by Brown \& Goldstein (1986) for the assay of saturable, high-affinity LDL binding. Liver plasma membranes were prepared from the livers of four hamsters randomly selected from each dietary group. Hamster livers were immediately put on ice and stored at $-70^{\circ}$. The preparation of liver membranes and the HDL binding studies were done as described for pig liver membranes (De Crom et al. 1989). Livers were minced on ice using surgical blades and homogenized in $0.25 \mathrm{M}$-sucrose, $1 \mathrm{mM}$-EDTA, $1 \mathrm{mM}$-benzamidine, $1 \mathrm{mM}$-phenylmethylsulfonylfluoride and 10 mM-Tris- $\mathrm{HCl}$, pH 8.0 using an Ultra Turrax TP 18-10 (Janke and Kunkel KG, Staufen, Germany). Tissue debris was removed by centrifugation in a Beckman TJ-6 centrifuge $\left(4^{\circ}, 5 \mathrm{~min}, 2000 \mathrm{rev} . / \mathrm{min}\right)$. The supernatant fraction was layered on a $410 \mathrm{~g} / \mathrm{l}$ sucrose solution and centrifuged in a Beckman SW 28 rotor (Beckman, Palo Alto, CA, USA) in a Beckman ultracentrifuge $\left(4^{\circ}, 60 \mathrm{~min}, 24000 \mathrm{rev} . / \mathrm{min}\right)$. The white interfacial band of membranes was collected and diluted by adding an excess of homogenization buffer. Subsequently, the membranes were pelleted by centrifugation ( $\left.4^{\circ}, 60 \mathrm{~min}, 24000 \mathrm{rev} . / \mathrm{min}\right)$. The membranes were washed and resuspended in a minimal volume of homogenization buffer and stored at $-70^{\circ}$. The final concentration of the liver membrane preparation was set at $2 \cdot 2 \mathrm{~g}$ protein $/ 1$.

In the HDL binding studies, we wanted to exclude any effect of the composition of the HDL particles. Therefore, we used human $\mathrm{HDL}_{3}$, since human $\mathrm{HDL}_{3}$ is a homogeneous, well-defined HDL fraction which can be easily prepared and stays stable for a long period of time. In addition, the plasma $\mathrm{HDL}_{3}$ concentration is usually higher than that of $\mathrm{HDL}_{2}$ which facilitates the preparation of larger quantities. Blood from one person was collected into tubes containing EDTA. $\mathrm{HDL}_{3}$ from fresh plasma was isolated and labelled with ${ }^{125} \mathrm{I}$ exactly as described by De Crom et al. (1989). HDL binding studies with liver membranes were performed in $50 \mathrm{mM}$ Tris- $\mathrm{HCl}$ buffer, $\mathrm{pH} 8 \cdot 0$, containing $50 \mathrm{mM}-\mathrm{NaCl}$ and $20 \mathrm{~g} / \mathrm{l}$ bovine serum albumin (binding assay buffer) in a final volume of $0.5 \mathrm{ml}$ as described by De Crom et al. (1989). Liver membrane protein $(100 \mu \mathrm{g})$ was incubated with ${ }^{125} \mathrm{I}$ labelled human $\mathrm{HDL}_{3}$ for $1 \mathrm{~h}$ at $37^{\circ}$ in Eppendorf tubes (Eppendorf, Hamburg, Germany). We elected to use an incubation temperature of $37^{\circ}$ since the binding capacity is considerably lower at lower temperatures (Fernandez \& McNamara, 1991) and we also considered that this temperature reflected better the in vivo situation. The reaction was terminated by adding $0.4 \mathrm{ml}$ cold binding assay buffer and centrifuging for $5 \mathrm{~min}$ in an Eppendorf 5414 centrifuge. Membrane pellets were resuspended in $0.4 \mathrm{ml}$ binding assay buffer, and layered over $0.4 \mathrm{ml}$ fetal calf serum and recentrifuged. The amount of radioactivity in the pellets was 
determined in an LKB Wallac Ultrogamma counter (LKB Wallac, Turku, Finland). The amount of membrane-associated radioactivity bound in the presence of 25 -fold excess of unlabelled ligand was regarded as nonspecific binding, and subtracted from the total binding to obtain specific binding. Scatchard plots were constructed and the maximal specific binding capacity of HDL to liver membranes ( $B_{\max }$, ng HDL protein/mg membrane protein) and the apparent affinity constant $\left(K_{\mathrm{d}}, \mathrm{mg}\right.$ HDL protein/l) were calculated from the slope and the intercepts.

\section{Hepatic lipase activity in hamster livers}

Livers were removed after exsanguination, quickly frozen in liquid $\mathrm{N}_{2}$ and kept at $-80^{\circ}$. About $100 \mathrm{mg}$ liver was homogenized in $4 \mathrm{ml} \mathrm{PBS}$, containing $5 \times 10^{3} \mathrm{U}$ heparin/l, using a Polytron homogenizer (Janke and Kunkel) for $15 \mathrm{~s}$. The homogenate was kept on ice and centrifuged for $2 \mathrm{~min}$ at $4^{\circ}(10000 \mathrm{~g})$. Hepatic lipase activity was determined in the supernatant fraction using a gum acacia-stabilized glycerol $\left[{ }^{14} \mathrm{C}\right]$ trioleate emulsion as described by Jansen \& Birkenhäger (1981).

\section{Statistics}

The data were analysed by one-way ANOVA. The Bonferroni adaptation of the $t$ test was used for multiple pairwise comparisons when the ANOVA test indicated a significant effect. Correlations between variables were statistically analysed with the Pearson product moment correlation test. The level of significance was preset at $P<0.05$. Statistical analyses were done with the SigmaStat ${ }^{\circledR}$ statistical software package (Jandel Scientific, San Rafael, CA, USA).

\section{Results}

The pelleted diets were well accepted by the animals. Final body weights after 9 weeks of consuming the diets were similar in the groups fed with palm oil or maize oil, but body weights were about $10 \%$ higher in the group fed with olive oil (Table 2). Liver weight was significantly greater in the olive-oil group than in the palm-oil group. We did not measure the food intake, but the higher body weights in the hamsters fed with olive oil may have been the result of a higher food intake. In other hamster studies in our laboratory, however, we did not observe any difference in body weights between hamsters fed on diets containing these three dietary fat types.

The hamsters fed on the diet containing maize oil had significantly lower total plasma, HDL-, and non-HDLcholesterol concentrations than the hamsters fed on the palm- and olive-oil diets (Table 2). The animals fed on the olive-oil diet tended to have lower values than the animals fed on the palm-oil diet, but this effect was not statistically significant. There was a significant positive correlation between the concentration of total plasma cholesterol and the concentration of cholesterol in HDL or non-HDL fractions in individual hamsters (Fig. 1). Thus, changes in total plasma cholesterol concentrations were reflected in changes in both HDL and non-HDL fractions.

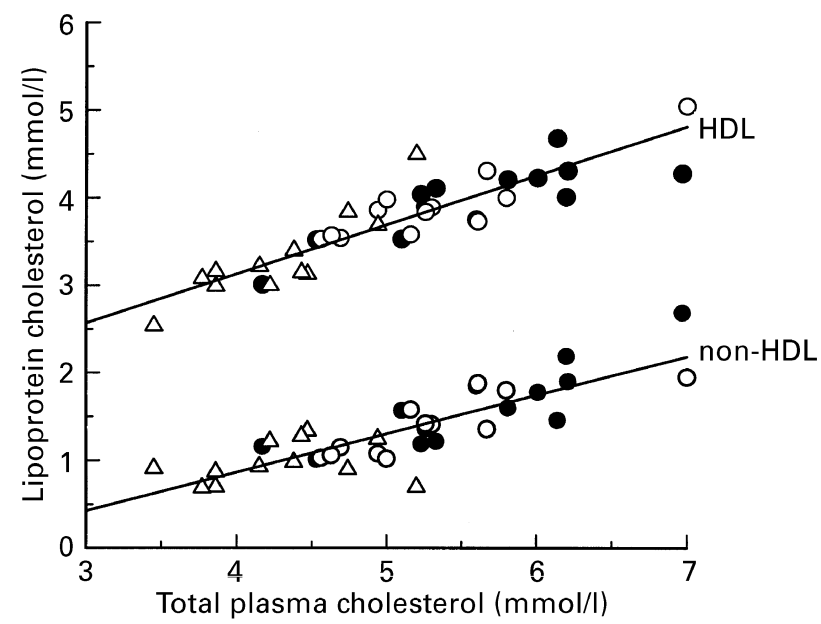

Fig. 1. Correlations between total plasma cholesterol concentration and the concentrations of HDL- and non-HDL-cholesterol fractions in hamsters fed on semipurified diets containing palm oil $(\bullet)$, maize oil $(\triangle)$ or olive oil $(O)$. The equations of the regression lines are: HDL cholesterol $=0.561 \times$ plasma cholesterol $+0.891(r 0.893, P<0.001)$ and non-HDL-cholesterol $=0.439 \times$ plasma cholesterol $-0.891(r 0.841$, $P<0.001)$

Further, the slopes of the regression lines for HDL and nonHDL fractions were fairly similar, indicating that a change in total plasma cholesterol was associated with equal changes in HDL- and non-HDL-cholesterol (Fig. 1). The hamsters fed with the maize oil had an average cholesterol level that was $1.29 \mathrm{mmol} / \mathrm{l}$ lower than that in the hamsters fed on the palm-oil diet, and this lowering was associated with equal decreases of HDL- $(0.66 \mathrm{mmol} / \mathrm{l})$ and non-HDLcholesterol $(0.63 \mathrm{mmol} / \mathrm{l})$. Plasma triacylglycerol concentrations were significantly lower in the maize- and olive-oil-fed hamsters compared with the palm-oil-fed hamsters, and there was no significant difference between the maize- and oliveoil groups (Table 2).

We did not observe a significant effect of dietary fat saturation on the activity levels of plasma LCAT and CETP (Table 2). LCAT activities were virtually the same in all three dietary groups. PLTP activity, however, showed a tendency to increase with increasing fat saturation, although these effects were not statistically significant. When all the hamsters were taken together, there was a significant correlation between PLTP activity and non-HDL-cholesterol concentration $(r 0.389, P=0.019)$ and PLTP activity and HDL-cholesterol concentration $(r 0 \cdot 509, P=0 \cdot 001)$.

Eight hamsters from each diet group were randomly selected to measure hepatic lipase activity in quicklyfrozen livers. Hepatic lipase activity was significantly higher in the hamsters fed with palm oil compared with the animals fed with maize oil (Table 2). The olive-oil-fed hamsters had intermediate activities. There was a significant correlation between hepatic lipase activity and total plasma and HDL-cholesterol concentrations in individual hamsters (Fig. 2).

Four hamsters per dietary group were used for assaying the HDL binding capacities $\left(\mathrm{B}_{\max }\right)$ and binding affinities $\left(K_{\mathrm{d}}\right)$ of liver membranes. Maximum HDL binding was found to be significantly higher in the hamsters fed with 
Table 2. Measures of cholesterol metabolism in hamsters fed on semipurified diets containing palm oil, olive oil or maize oil for a period of 9 weeks*

(Mean values and standard deviations for four, eight or twelve hamsters per group)

\begin{tabular}{|c|c|c|c|c|c|c|}
\hline & \multicolumn{2}{|c|}{ Palm oil } & \multicolumn{2}{|c|}{ Olive oil } & \multicolumn{2}{|c|}{ Maize oil } \\
\hline & Mean & SD & Mean & SD & Mean & SD \\
\hline \multicolumn{7}{|l|}{ Plasma and liver variables $(n 12) \dagger$} \\
\hline \multicolumn{7}{|l|}{ Plasma cholesterol (mmol/l) } \\
\hline Initial & $3 \cdot 23$ & 0.36 & $3 \cdot 31$ & 0.43 & $3 \cdot 24$ & 0.44 \\
\hline Final & $5.58^{a}$ & 0.76 & $5 \cdot 30^{a}$ & 0.67 & $4.29^{b}$ & 0.51 \\
\hline HDL-cholesterol (mmol/l) & $3.97^{\mathrm{a}}$ & 0.43 & $3.91^{\mathrm{a}}$ & 0.12 & $3 \cdot 31^{b}$ & 0.50 \\
\hline Non-HDL-cholesterol (mmol/l) & $1.61^{\mathrm{a}}$ & 0.47 & $1.40^{\mathrm{a}}$ & 0.34 & $0.98^{\mathrm{b}}$ & 0.24 \\
\hline Plasma triacylglycerols $(\mathrm{mmol} / \mathrm{l})$ & $2.75^{\mathrm{a}}$ & 1.03 & $1.56^{\mathrm{b}}$ & 0.65 & $1.01^{\mathrm{b}}$ & 0.59 \\
\hline LCAT $(\mu \mathrm{mol} / \mathrm{l}$ per $\mathrm{h})$ & 77 & 16 & 78 & 15 & 78 & 13 \\
\hline CETP ( $\mu \mathrm{mol} / / \mathrm{per} h)$ & 136 & 24 & 129 & 15 & 142 & 21 \\
\hline PLTP (mmol// per h) & 6.97 & 1.67 & 6.29 & 1.32 & 5.99 & 1.19 \\
\hline Liver weight $(\mathrm{g})$ & $4 \cdot 6^{\mathrm{b}}$ & 0.7 & $5 \cdot 5^{a}$ & 0.8 & $4 \cdot 8^{\mathrm{ab}}$ & 0.9 \\
\hline Liver weight (\% body weight) & $3.51^{b}$ & 0.27 & $3.85^{a}$ & 0.29 & $3.66^{\mathrm{ab}}$ & 0.31 \\
\hline \multicolumn{7}{|l|}{ Body weight $(\mathrm{g})$} \\
\hline Initial & 73 & 8 & 72 & 8 & 73 & 7 \\
\hline Final & $129^{b}$ & 13 & $141^{\mathrm{a}}$ & 12 & $129^{b}$ & 17 \\
\hline \multicolumn{7}{|c|}{ Subgroup for determination of lipase activity $(n 8)$} \\
\hline \multicolumn{7}{|c|}{ Plasma cholesterol $(\mathrm{mmol} / \mathrm{l})$} \\
\hline Initial & 3.24 & 0.33 & 3.38 & 0.49 & $3 \cdot 17$ & 0.41 \\
\hline Final & $5.57^{a}$ & 0.67 & $5 \cdot 10^{\mathrm{ab}}$ & 0.47 & $4.42^{\mathrm{b}}$ & 0.47 \\
\hline HDL-cholesterol (mmol/l) & $3.94^{\mathrm{a}}$ & 0.42 & $3.75^{\mathrm{ab}}$ & 0.18 & $3.38^{b}$ & 0.51 \\
\hline Non-HDL-cholesterol (mmol/l) & $1.63^{\mathrm{a}}$ & 0.36 & $1 \cdot 35^{\mathrm{ab}}$ & 0.34 & $1.04^{b}$ & 0.26 \\
\hline Hepatic lipase activity (mU/g liver) $\ddagger$ & $148 \cdot 1^{\mathrm{a}}$ & $19 \cdot 2$ & $134 \cdot 6^{\mathrm{ab}}$ & 17.9 & $111.3^{\mathrm{b}}$ & 17.7 \\
\hline Hepatic lipase activity ( $\mathrm{mU} / \mathrm{mg}$ protein) & $0.62^{a}$ & 0.11 & $0.58^{a}$ & 0.08 & $0.45^{b}$ & 0.10 \\
\hline \multicolumn{7}{|c|}{ Subgroup for determination of binding variables $(n 4)$} \\
\hline \multicolumn{7}{|c|}{ Plasma cholesterol $(\mathrm{mmol} / \mathrm{l})$} \\
\hline Initial & 3.36 & 0.41 & 3.22 & 0.31 & 3.15 & 0.57 \\
\hline Final & $5.77^{\mathrm{a}}$ & 0.42 & $5.07^{\mathrm{ab}}$ & 0.59 & $4.48^{b}$ & 0.55 \\
\hline HDL-cholesterol (mmol/l) & $4 \cdot 05^{a}$ & 0.27 & $3 \cdot 75^{\mathrm{a}}$ & 0.23 & $3.51^{\mathrm{a}}$ & 0.68 \\
\hline Non-HDL-cholesterol (mmol/l) & $1.72^{\mathrm{a}}$ & 0.25 & $1.33^{\mathrm{ab}}$ & 0.36 & $0.97^{b}$ & 0.27 \\
\hline \multicolumn{7}{|l|}{ Human $\mathrm{HDL}_{3}$ binding variables } \\
\hline $\begin{array}{l}\mathrm{B}_{\text {max }} \text { (ng HDL protein/mg membrane } \\
\text { protein) }\end{array}$ & $655^{\mathrm{b}}$ & 56 & $674^{\mathrm{ab}}$ & 26 & $810^{a}$ & 100 \\
\hline$K_{\mathrm{d}}(\mathrm{mg} \mathrm{HDL}$ protein/l) & $11 \cdot 8$ & $1 \cdot 7$ & $11 \cdot 8$ & 1.4 & $13 \cdot 4$ & 1.0 \\
\hline
\end{tabular}

maize oil than in those fed with palm oil. The olive-oil group had intermediate values but this effect was not significant (Table 2). There was a significant correlation between binding capacities $\left(\mathrm{B}_{\max }\right)$ and total plasma and HDL-cholesterol concentrations (Fig. 3). The affinities for HDL binding $\left(K_{\mathrm{d}}\right)$ did not differ among the three dietary groups.

\section{Discussion}

Intervention studies in human subjects (McNamara, 1992; Khosla \& Sundram, 1996) have indicated that unsaturated fatty acids compared with saturated fatty acids in the diet lower plasma cholesterol levels, and that this effect is associated with a lowering of both LDL- and HDL-cholesterol levels. The objective of our present study was to examine the mechanism by which unsaturated fatty acids lower plasma cholesterol and particularly HDL-cholesterol levels. We elected to use the hamster as a model for the human situation, since the hamster has a lipoprotein profile that resembles closely that of man (Bravo et al. 1994) and has CETP activity (Stein et al. 1990) like man. The hamster has been widely used to study the effect of dietary fatty acids on lipoprotein metabolism (Dietschy et al. 1993; Khosla \& Sundram, 1996), and the results of our studies indicate that the hamster responds to dietary fatty acids in a similar fashion to human subjects. Substitution of unsaturated fatty acids (maize oil) for saturated fatty acids (palm oil) resulted in a lowering of the total plasma cholesterol level which was associated with a lowering in both nonHDL- and HDL-cholesterol fractions (Fig. 1), as seen in studies with human subjects (Mattson \& Grundy, 1985). Other studies in hamsters have also indicated that cholesterol-enriched diets containing polyunsaturated fattty acids instead of saturated fat are effective in lowering both HDLand non-HDL-cholesterol levels (Jones et al. 1990; Ahn et al. 1994; Trautwein et al. 1997). 


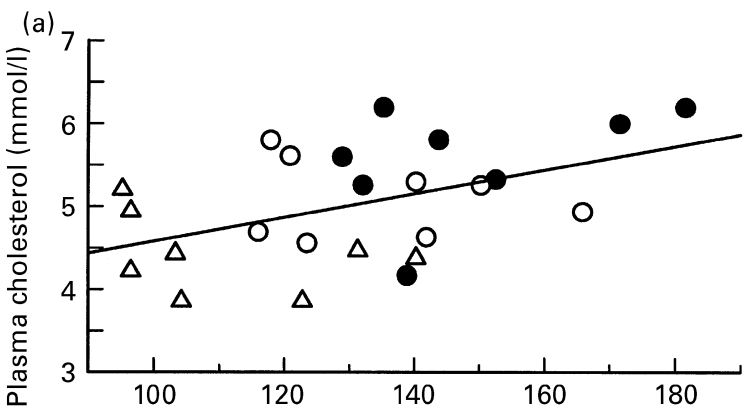

(b)

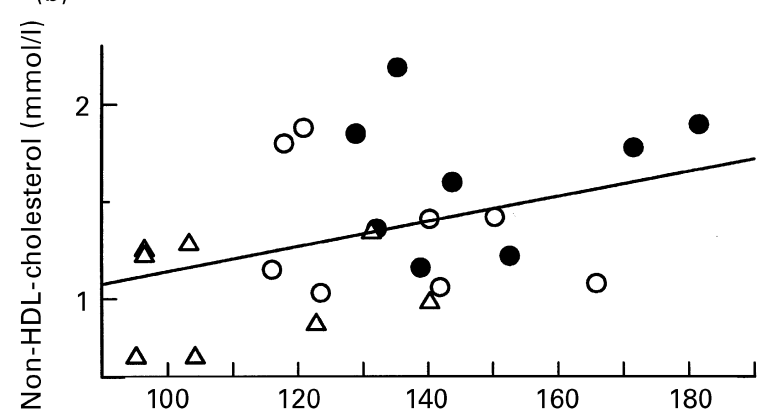

(c)

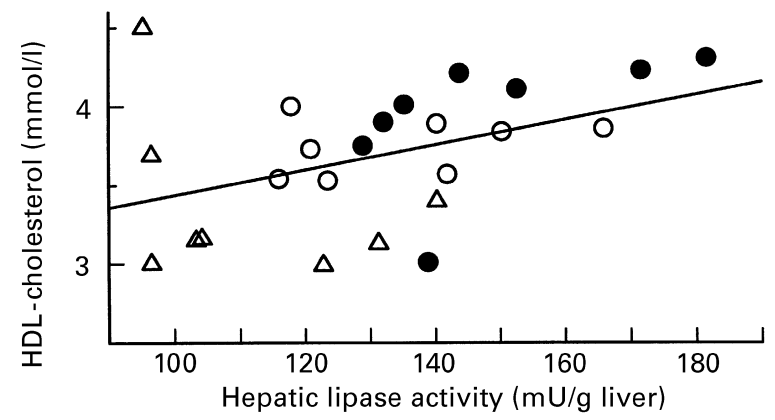

Fig. 2. Correlations between hepatic lipase activity and the concentrations of (a) total plasma cholesterol, (b) non-HDL-cholesterol, and (c) HDL-cholesterol in hamsters fed on semipurified diets containing palm oil $(\bullet)$, maize oil $(\triangle)$ or olive oil $(O)$. The relationships are described by the equations: (a), $y=0.014 x+3.133$ ( $r$ 0.475, $P=$ $0.019)$; (b), $y=0.006 x+0.494(r 0.383, P=0.065)$; (c) $y=0.008 x$ $+2.640(r 0.418, P=0.042)$.

Olive oil tended to lower plasma cholesterol levels in our studies but this effect was not statistically significant. Trautwein et al. (1997) also reported that feeding hamsters with olive oil instead of palm stearin or coconut oil together with cholesterol for a period of 7 weeks did not significantly lower plasma cholesterol. Further, Trautwein et al. (1997) observed that changes in total plasma cholesterol levels due to different types of dietary fats, were associated with changes in both HDL- and non-HDL-cholesterol fractions, as seen in the present study (Fig. 1). Jones et al. (1990) and Kurushima et al. (1995), however, found that olive oil and oleic acid respectively, significantly lowered plasma cholesterol levels in hamsters without lowering HDL-cholesterol. We fed our hamsters on semipurified diets and similar diets were used by Trautwein et al. (1997). Jones et al. (1990) and Kurushima et al. (1995), on the other hand, used chowbased diets, and it has been demonstrated that these two
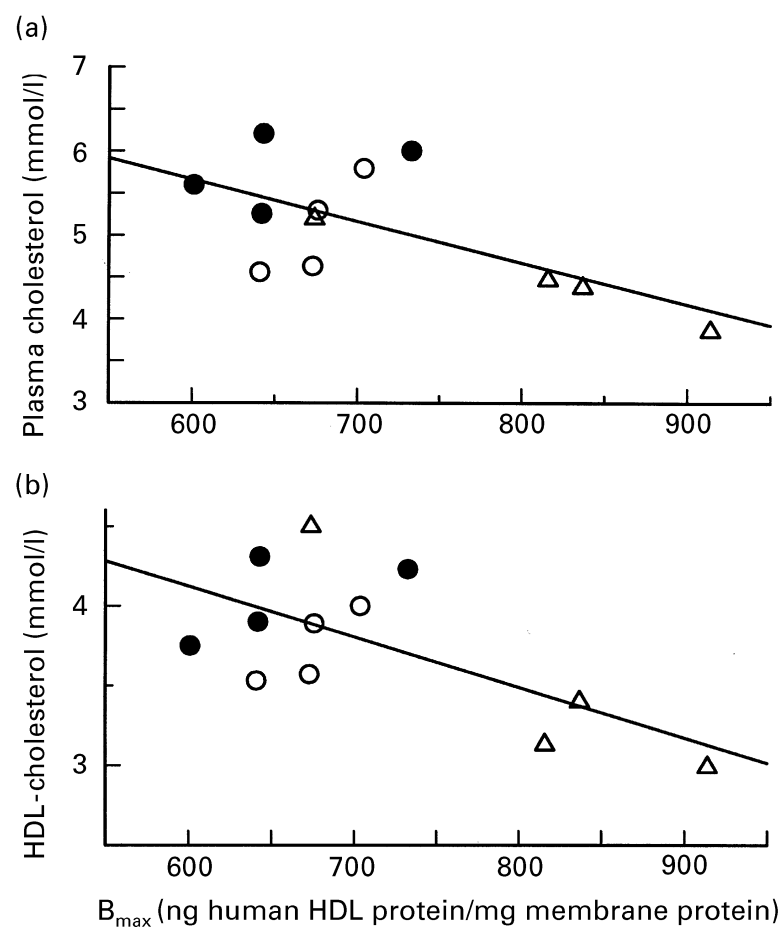

Fig. 3. Correlations between maximum binding capacity $\left(B_{\max }\right)$ and the concentrations of (a) total plasma cholesterol and (b) HDLcholesterol in hamsters fed on semipurified diets containing palm oil $(\bullet)$, maize oil $(\triangle)$ or olive oil $(\bigcirc)$. The relationships are described by the equations; (a), $y=-0.005 x+8.635$ ( $r$ 0.645, $P=0.024)$; (b), $y=$ $-0.003 x+6.026(r 0.647, P=0.023)$.

types of diets may have different effects on the lipoprotein profile in hamsters after dietary intervention (Kowala, 1993; Nicolosi et al. 1998). Studies in human subjects are also conflicting. Mensink \& Katan (1989) reported that monounsaturated and polyunsaturated fatty acids were similarly effective in lowering plasma total cholesterol levels and that both also lowered HDL-cholesterol levels. Studies by Mattson \& Grundy (1985), on the other hand, indicated that monounsaturated fatty acids compared with polyunsaturated fatty acids raised HDL-cholesterol levels.

Liver weights and liver weights as a percentage of body weight were higher in the olive-oil-fed hamsters than in the hamsters fed with palm oil or maize oil, althought this effect was not statistically significant for the maize-oil group. We did not measure liver cholesterol, but other studies have indicated that feeding olive oil instead of saturated or polyunsaturated fats also resulted in a higher content of liver cholesterol (Beynen, 1988). The high cholesterol content in the liver of olive-oil-fed hamsters may be related to abundant availability of oleate, the preferred substrate for acyl-CoA : cholesterol acyltransferase (EC 2.3.1.26), the cholesterol esterifying enzyme in the liver (Dietschy, 1998).

In the present study there was no effect of type of fat in diets containing $1 \mathrm{~g}$ cholesterol/kg on plasma CETP and LCAT activity levels. Similar results have been reported in other hamster studies (Ahn et al. 1994). Kurushima et al. (1995), on the other hand, reported a higher CETP activity in hamsters fed with saturated fatty acids instead of polyunsaturated fatty acids. Other studies in hamsters also 
showed that an increase in plasma cholesterol concentrations as caused by feeding high-saturated fat, cholesterolrich diets was associated with elevated CETP levels (Stein et al. 1990; Quig et al. 1991). In human subjects, Lottenberg et al. (1996) reported that there was no differential effect of diets containing mono- or polyunsaturated fatty acids on CETP activity. Groener et al. (1991), on the other hand, reported higher CETP activities in subjects on polyunsaturated fat diets than those on monounsaturated fat diets, and other studies in human subjects (van Tol et al. 1995; Schwab et al. 1996; Lagrost et al. 1999) also indicated that different fatty acids in the diet such as palmitic, stearic, lauric, oleic and elaidic acids can affect CETP activity. Reports on the effects of dietary fat saturation on LCAT activity in human subjects are also conflicting. Baudet \& Jacotot (1988) found a higher LCAT activity when polyunsaturated fats (sunflower oil) were given instead of saturated fats (milk fat) but they discussed that there are also studies that found the opposite effect. van Tol et al. (1995) reported that there was no differential effect of polyunsaturated fat (linoleic acid) and saturated fat (stearic acid) on LCAT activity in human subjects. As plasma LCAT and CETP activity levels in our studies were not significantly influenced by dietary fat saturation, the observed changes in HDL-cholesterol are unlikely to have been caused by changes in cholesterol ester synthesis and transfer.

Plasma PLTP activity levels were measured using excess exogenous substrates. To our knowledge, this is the first report on PLTP activity levels in animals fed on different types of fat. The PLTP activities were not significantly different for the three different dietary fatty acid profiles but there was a tendency for increasing PLTP activity with increasing fat saturation. Moreover, when all the hamsters were taken together, there was a significant positive correlation between PLTP activity and HDL- as well as non-HDLcholesterol levels. In human subjects, it has been reported that various dietary fatty acids like palmitic, lauric, and oleic acid can affect PLTP activities and that there was also a positive correlation between HDL-cholesterol and PLTP activities (Lagrost et al. 1999). Two possible functions of PLTP in lipoprotein metabolism have been proposed. First, PLTP may act in the transfer of surface fragments, formed during lipolysis of triacylglycerol-rich lipoproteins to HDL (Tall et al. 1985). Second, PLTP is active in HDL subfraction conversion (Jauhiainen et al. 1993). Isolated $\mathrm{HDL}_{3}$ is converted by purified PLTP to bigger $\mathrm{HDL}_{2}$-like HDL, with the concomitant formation of small pre- $\beta$-HDL (von Eckardstein et al. 1996).

Hepatic lipase activity was significantly higher in the hamsters fed with palm oil when compared with the maizeoil group. Hepatic lipase plays a role in the conversion of LDL and HDL subfractions (Syvanne \& Taskinen, 1997). Studies in human subjects have shown that hepatic lipase activity and HDL-cholesterol concentrations are inversely related (Bensadoun \& Berryman, 1996). In the present study with hamsters, however, there was a positive correlation between HDL-cholesterol concentration and hepatic lipase activity. Similarly, Jansen et al. (1989) described in the hamster an increase in liver-bound hepatic lipase activity after feeding cholesterol, which in the hamster is usually associated with increases in both total plasma cholesterol and HDL-cholesterol levels. Further, it is known that addition of VLDL- and LDL-cholesterol to the perfusate may increase hepatic lipase levels in a recirculating liver perfusion system (Ebert et al. 1993). Rabbits respond to cholesterol feeding by elevation of hepatic lipase activities (Meijer et al. 1993). These data are consistent with our observation that in the hamsters fed with palm oil, high plasma nonHDL-cholesterol concentrations coincided with high hepatic lipase activities. We suggest that increased hepatic lipase activity is secondary to the increase in non-HDL-cholesterol.

Little is known about the effects of dietary fats on HDL binding to liver membranes. Fernandez \& McNamara (1991) observed that dietary unsaturated $v$. saturated fatty acids increased the binding capacity of liver membranes for HDL in the guinea-pig. We have now shown in hamsters that dietary maize oil raised $\mathrm{B}_{\max }$ when compared with palm oil. These results indicate that there was an increase in the number of HDL binding sites on the liver membranes.

HDL plays an important role in reverse cholesterol transport (Swenson, 1992), and an increase in HDL binding to liver membranes may stimulate this process. Early kinetic studies in human subjects indeed suggested an increased transport rate of HDL cholesteryl esters when saturated fat in the diet was replaced by unsaturated fat (Nestel, 1970). Thus, the observation that maize oil compared with palm oil significantly enhanced HDL binding to liver membranes could explain why dietary maize oil lowers HDL-cholesterol levels in the hamster.

We used the hamster as a model to study the effects of dietary fat saturation on plasma cholesterol and HDL metabolism. Eventually, this model is meant to obtain information about the human situation. It should be stressed, however, that there may be differences in responses to dietary fats when compared with human subjects and one should be careful in extrapolating results obtained in hamsters to man. For instance, in our present study there was a significant lowering in plasma triacylglycerol levels with decreasing fat saturation, whereas no such findings are reported in man (Khosla \& Sundram, 1996). Further, we found in hamsters a positive correlation between HDLcholesterol level and hepatic lipase activity, whereas in human subjects a negative correlation has been reported (Bensadoun \& Berryman, 1996). These different responses may reflect a difference in lipid metabolism between human subjects and hamsters. In addition, there may also be differences in response between various strains of hamsters (Trautwein et al. 1993) and the effects may also be modulated by the type of diets used, i.e. semipurified $v$. chow-based diets (Kowala, 1993; Nicolosi et al. 1998). Differences between hamster strains and types of diet may also explain why there were no effects of fat saturation on CETP activity in our studies and the studies of Ahn et al. (1994), while there were effects in other studies (Kurushima et al. 1995).

\section{Acknowledgements}

These studies were supported by a grant from the Netherlands Heart Foundation (grant no. 93.122). We acknowledge Piet Roeleveld (TNO-ILOB, Wageningen, The Netherlands) for preparing the semipurified diets, Cees J.W.M. Brandt 
(Animal Laboratory, Utrecht University, The Netherlands) for biotechnical assistance and Inez Lemmens and Roti Opitz (Department of Laboratory Animal Science, Utrecht University, The Netherlands) for technical assistance. Ina Kalkman, Leo M. Scheek, and Teus van Gent (Department of Biochemistry, Erasmus University Rotterdam, The Netherlands) are acknowledged for their assistance in the analyses of hepatic lipase, LCAT and CETP activities respectively.

\section{References}

Ahn Y-S, Smith D, Osada J, Li Z, Schaefer EJ \& Ordovas JM (1994) Dietary fat saturation affects apolipoprotein gene expression and high density lipoprotein size distribution in Golden Syrian hamster. Journal of Nutrition 124, 2147-2155.

Allain CC, Poon LS, Chen CGS \& Richmond W (1974) Enzymatic determination of total cholesterol. Clinical Chemistry 20, 476482.

Baudet MF \& Jacotot B (1988) Dietary fats and lecithin-cholesterol acyltransferase activity in healthy humans. Annals of Nutrition and Metabolism 32, 352-359.

Bensadoun A \& Berryman DE (1996) Genetics and molecular biology of hepatic lipase. Current Opinion in Lipidology 7, $77-$ 81 .

Beynen AC (1988) Dietary monounsaturated fatty acids and liver cholesterol. Artery 15, 170-175.

Bravo E, Cantafora A, Calccabrini A \& Ortu G (1994) Why prefer the Golden Syrian hamster (Mesocritus auratus) to the Wistar rat in experimental studies on plasma lipoprotein metabolism? Comparative Biochemistry and Physiology 107B, 347-355.

Brown MS \& Goldstein JL (1986) A receptor mediated pathway for cholesterol homeostasis. Science 232, 34-37.

Bucolo G \& David H (1973) Quantitative determination of serum triglycerides by the use of enzymes. Clinical Chemistry 19, 476482.

De Crom MPG, van Haperen MJ, Puchois P, Fruchart J-C, van Gent T, van Tol A \& van der Kamp AWM (1989) Binding characteristics of high density lipoprotein subclasses to porcine liver, adrenal and skeletal muscle plasma membranes. International Journal of Biochemistry 21, 649-656.

Dietschy JM (1998) Dietary fatty acids and the regulation of plasma low density lipoprotein cholesterol concentrations. Journal of Nutrition 128, 444S-448S.

Dietschy JM, Turley SD \& Spady DK (1993) Role of liver in the maintenance of cholesterol and low density lipoprotein homeostasis in different animal species, including humans. Journal of Lipid Research 34, 1637-1659.

Dullaart RPF, Sluiter WJ, Dikkeschei LD, Hoogenberg K \& van Tol A (1994) Effect of adiposity on plasma lipid transfer protein activities: a possible link between insulin resistance and high density lipoprotein metabolism. European Journal of Clinical Investigation 24, 188-194.

Ebert DL, Warren RJ, Barter PJ \& Mitchell A (1993) Infusion of atherogenic lipoprotein particles increases hepatic lipase activity in the rabbit. Journal of Lipid Research 34, 89-94.

Fernandez ML \& McNamara DJ (1991) Characterization of highdensity lipoprotein binding to guinea pig hepatic membranes: effects of dietary fat quality and cholesterol feeding. Metabolism 40, 127-134

Groener JEM, Pelton RW \& Kostner GM (1986) Improved estimation of cholesteryl ester transfer/exchange activity in serum or plasma. Clinical Chemistry 32, 283-286.

Groener JEM, van Ramshorst EM, Katan MB, Mensink RP \& van Tol A (1991) Diet-induced alteration in the activity of plasma lipid transfer protein in normolipidemic human subjects. Atherosclerosis 87, 221-226.
Jansen H \& Birkenhäger JC (1981) Liver lipase-like activity in human and hamster adrenocorticol tissue. Metabolism 30, 428430.

Jansen H, Lammers R, Baggen MGA, Wouters NMH \& Birkenhäger JC (1989) Circulating and liver-bound salt resistant hepatic lipases in the golden hamster. Biochimica et Biophysica Acta 1001, 44-49.

Jauhiainen M, Metso J, Pahlman R, Blomqvist S, van Tol A \& Ehnholm C (1993) Human plasma lipid transfer protein causes high density lipoprotein conversion. Journal of Biological Chemistry 268, 4032-4036.

Jones PJH, Ridgen JE \& Benson AP (1990) Influence of dietary fatty acid composition on cholesterol synthesis and esterification in hamsters. Lipids 25, 815-820.

Khosla P \& Sundram K (1996) Effect of dietary fatty acid composition on plasma cholesterol. Progress in Lipid Research 35, 93-132.

Kowala MC (1993) Effect of an atherogenic diet on lipoprotein cholesterol profile in the F1B hybrid hamster. Atherosclerosis 103, 293-294.

Kurushima H, Hayaki K, Shingu T, Shingu T, Kugu Y, Ohtani H, Okura Y, Tanaka K, Yasunobu Y, Nomura K \& Kajiyama G (1995) Opposite effects on cholesterol metabolism and their mechanisms induced by dietary oleic acid and palmitic acid in hamsters. Biochimica et Biophysica Acta 1258, 251-256.

Lagrost L, Mensink RP, Guyard-Dangremont V, Temme EHM, Desmuraux C, Athias A, Hornstra G \& Gambert P (1999) Variations in serum cholesteryl ester transfer and phospholipid transfer activities in healthy women and men consuming diets enriched in lauric, palmitic or oleic acids. Atherosclerosis $\mathbf{1 4 2}$, 395-402.

Lottenberg AMP, Nunes VS, Lottenberg SA, Shimabukuro AFM, Carrilho AJF, Malagutti S, Nakandakare ER, McPherson R \& Quintao ECR (1996) Plasma cholesteryl ester synthesis, cholesteryl ester transfer protein concentration and activity in hypercholesterolemic women. Effects of the degree of saturation of dietary fatty acids in the fasting and postprandial states. Atherosclerosis 126, 265-275.

McNamara DJ (1992) Dietary fatty acids, lipoproteins and cardiovascular disease. Advances in Lipid Research 36, 253-351.

Mattson FH \& Grundy SM (1985) Comparison of effects of dietary saturated, monounsaturated, and polyunsaturated fatty acids on plasma lipids and lipoproteins in man. Journal of Lipid Research 26, 194-202.

Meijer GW, Demacker PNM, van Tol A, Groener JEM, van der Palen JGP, Stalenhoef AFH, van Zutphen LMF \& Beynen AC (1993) Plasma activities of lecithin:cholesterol acyltransferase, lipid transfer protein and post-heparin lipases in inbred strain of rabbits hypo- and hyper responsive to dietary cholesterol. Biochemical Journal 293, 729-734.

Mensink RP \& Katan MB (1989) Effect of a diet enriched with monounsaturated or polyunsaturated fatty acids on levels of lowdensity and high-density lipoprotein cholesterol in healthy women and men. New England Journal of Medicine 321, 436-441.

Nestel PJ (1970) Turnover of plasma esterified cholesterol: influence of dietary fat and carbohydrate and relation to plasma lipids and body weight. Clinical Science 38, 593-600.

Nicolosi RJ, Wilson TA, Lawton C, Rogers EJ, Wiseman SA, Tijburg LBM \& Kritchevsky D (1998) The greater atherogenicity of nonpurified diets versus semipurified diets in hamsters is mediated via differences in plasma lipoprotein cholesterol distribution, LDL oxidative susceptibility, and plasma $\alpha$-tocopherol concentration. Journal of Nutritional Biochemistry 9, 591-597.

Quig DW, Arbeeney CM \& Zilversmit DB (1991) Effects of hyperlipidemias in hamsters on lipid transfer protein activity and unidirectional cholesteryl ester transfer in plasma. Biochimica et Biophysica Acta 1083, 257-264. 
Schwab US, Maliranta HM, Sarkkinen ES, Savolainen MJ, Kesaniemi YA \& Uusitupa MIJ (1996) Different effects of palmitic and stearic acid-enriched diets on serum lipids and lipoproteins and plasma cholesteryl ester transfer protein activity in healthy young women. Metabolism 45, 143-149.

Sessions VA \& Salter AM (1995) Low density lipoprotein binding to monolayer cultures of hepatocytes isolated from hamsters fed different dietary fatty acids. Biochimica et Biophysica Acta $\mathbf{1 2 5 8}$, 61-69.

Speijer H, Groener JEM, van Ramshorst E \& van Tol A (1991) Different locations of cholesteryl ester transfer protein and phospholipid transfer protein activities in plasma. Atherosclerosis $\mathbf{9 0}$, 159-168.

Stein Y, Dabach Y, Hollander G \& Stein O (1990) Cholesteryl ester transfer activity in hamster plasma: increase by fat and cholesterol rich diets. Biochimica et Biophysica Acta 1042, $138-141$.

Swenson TL (1992) Transfer proteins in reverse cholesterol transport. Current Opinion in Lipidology 3, 67-74.

Syvanne M \& Taskinen M-R (1997) Lipids and lipoproteins as coronary risk factors in non-insulin-dependent diabetes mellitus. Lancet 350, Suppl. 20-23.

Tall AR, Krumholz S, Olivecrona T \& Deckelbaum RJ (1985)
Plasma phospholipid transfer protein enhances transfer and exchange of phospholipids between very low density lipoproteins and high density lipoproteins during lipolysis. Journal of Lipid Research 26, 842-851.

Trautwein EA, Liang J \& Hayes KC (1993) Cholesterol gallstone induction in hamsters reflects strain differences in plasma lipoproteins and bile acid profiles. Lipids 28, 305-312.

Trautwein EA, Kunath-Rau A, Dietrich J, Drusch S \& Erbersdobler HF (1997) Effect of dietary fats rich in lauric, myristic, palmitic. oleic or linoleic acid on plasma, hepatic and biliary lipids in cholesterol-fed hamsters. British Journal of Nutrition 77, 605620.

van Tol A, Zock PL, van Gent T, Scheek LM \& Katan MB (1995) Dietary trans fatty acids increase serum cholesterylester transfer protein activity in man. Atherosclerosis 115, 129-134.

von Eckardstein A, Jauhiainen M, Huang Y, Metso J, Langer C, Pussinen P, Wu S, Ehnholm C \& Assmann G (1996) Phospholipid transfer protein mediated conversion of high density lipoproteins generates pre beta 1-HDL. Biochimica et Biophysica Acta 1301, 255-262.

Weingand KW \& Daggy BP (1990) Quantification of high-densitylipoprotein cholesterol in plasma from hamsters by differential precipitation. Clinical Chemistry 36, 575. 